\title{
DERECHO ELECTORAL
}

\section{La privación del derecho de sufragio pasivo. Caso: López Mendoza contra Venezuela. Comentario de jurisprudencia}

\author{
Luis Guillermo Palacios Sanabria* \\ https://doi.org/10.35242/RDE $2022 \quad 2233 \quad 12$
}

Nota del Consejo Editorial

Recepción: 13 de octubre de 2021.

Revisión, corrección y aprobación: 14 de enero de 2022.

Resumen: En el presente comentario se exponen algunas consideraciones sobre la sentencia $\mathrm{n} .^{\circ} 233$ (serie c) de la Corte Interamericana de Derechos Humanos, de fecha 01 de septiembre de 2011, la cual resuelve la petición del ciudadano venezolano Leopoldo López Mendoza, quien en 2008 fue inhabilitado para el ejercicio de la función pública por parte de la Contraloría General de la República, principal órgano del sistema nacional de control fiscal del Estado venezolano. En consecuencia, se analiza la procedencia de inhabilidades públicas impuestas en sede administrativa conforme a la Convención Americana sobre Derechos Humanos y los alcances y límites de los derechos políticos contemplados por el Sistema Interamericano de Derechos Humanos.

Palabras clave: Cargos públicos / Cargos de elección popular / Inhabilitación / Derechos políticos / Sufragio pasivo / Resoluciones administrativas / Venezuela.

\begin{abstract}
The present remarks present some considerations about sentence n. ${ }^{\circ} 233$ (series c) of the Inter-American Court of Human Rights, dated September $1^{\text {st }}, 2011$, which resolves the request from the Venezuelan citizen, Leopoldo López Mendoza, who was disqualified from holding public posts, by the Comptroller's Office, which is Venezuela's main institution of fiscal control. This work analyzes the origin of public disqualification imposed on the administrative head office according to the American Convention of Human Rights and the reach and boundaries of the political rights contemplated by the Inter-American system.
\end{abstract}

Key Words: Public posts / Popular election posts / Disqualification / Political rights / Passive suffrage / Administrative resolutions / Venezuela.

\footnotetext{
*Venezolano, abogado, correo Luis.palacios@uss.cl. Académico regular de planta de la Facultad de Derecho y Gobierno de la Universidad San Sebastián, sede Valdivia (Chile). Candidato a doctor en Derecho Mención Constitucionalismo y Derecho por la Universidad Austral de Chile.
} 


\section{DERECHO ELECTORAL}

\section{Contexto: Caso López Mendoza vs. Venezuela}

En Venezuela el control, vigilancia y fiscalización de los ingresos, gastos, bienes públicos y bienes nacionales corresponde, por mandato del artículo 287 de la Constitución, a la Contraloría General de la República (CGR), un órgano de control que goza nominalmente de autonomía funcional, administrativa y organizativa. Su función más relevante se expresa en el ejercicio de inspecciones sobre los organismos públicos y demás sujetos sometidos a su control; y la declaratoria de responsabilidad e imposición de sanciones administrativas cuando corresponda. Su régimen normativo central se encuentra en la Ley Orgánica de la Contraloría General de la República y del Sistema Nacional de Control Fiscal (LOCGRSNCF) del año 2001.

Dicho instrumento legal articula los medios de sanción a disposición del órgano contralor, el cual puede, entre otras cosas: suspender la relación de empleo público sin goce de sueldo por un periodo máximo de veinticuatro meses, acordar la destitución del o los funcionarios en atención al ilícito cometido y la más grave por la afectación de derechos que implica la inhabilitación para el ejercicio de funciones públicas.

En ejercicio de sus funciones, la CGR en el año 2004 inició contra el político venezolano Leopoldo López Mendoza un par de procedimientos administrativos destinados a la determinación de responsabilidad fiscal. Finalmente, a López Mendoza se le impusieron dos sanciones administrativas que consistieron en una multa, y luego le fue aplicada, por el contralor, la sanción accesoria de inhabilitación para ejercer función pública por periodos de 3 y 6 años. Estas decisiones administrativas fueron recurridas por el afectado hasta llegar a la Sala PolíticoAdministrativa del Tribunal Supremo de Justicia, sin obtener una respuesta favorable a su pretensión.

En marzo de 2008 López Mendoza formalizó ante la Comisión Interamericana de Derechos Humanos (CIDH) una petición contra su inhabilitación para el ejercicio de la función pública. Dicha inhabilitación fue impuesta por la Contraloría General de la República, un órgano de carácter administrativo que integra el Sistema Nacional de Control Fiscal de Venezuela. Atendiendo el procedimiento, en agosto de 2009, la CIDH emitió el Informe de Fondo n. ${ }^{\circ}$ 92/09 y lo remitió al Estado venezolano, quien dispuso de un plazo de dos meses para dar cuenta de las medidas de cumplimiento a las recomendaciones de la Comisión (Gómez, 2011). 


\section{DERECHO ELECTORAL}

Posteriormente, y verificado el incumplimiento por parte de Venezuela, la CIDH accedió a presentar el caso ante la Corte Interamericana de Derechos Humanos (Corte IDH), en el que se demandó la responsabilidad internacional del Estado por contravenir las disposiciones normativas de la Convención Americana sobre Derechos Humanos. Puntualmente, la CIDH en su petición a la Corte IDH precisó:

...al momento de adoptar la decisión de inhabilitación para el ejercicio de la función pública de López Mendoza, el Contralor General de la República y, en revisión, la Sala Político Administrativa del Tribunal Supremo de Justicia, no elaboraron argumentos adicionales que sustentaran la aplicación de una sanción más gravosa a una multa previamente impuesta, ni ofrecieron argumentos que calificaran el tipo de conducta ilícita y su correspondencia con la imposición de una de las máximas sanciones accesorias.

Satisfechos los requerimientos procesales inherentes a la jurisdicción del Sistema Interamericano, el primero de septiembre de 2011 la Corte IDH dictó sentencia y, en consecuencia, tal como refiere el fallo n. ${ }^{\circ} 233$ (serie c), dictaminó la responsabilidad del Estado venezolano por los siguientes perjuicios al ciudadano Leopoldo López Mendoza:

1. Violación del derecho a ser elegido, establecido en los artículos 23.1 y 23.2 de la Convención.

2. Violación del deber de motivación y el derecho a la defensa en los procedimientos administrativos, establecidos en el artículo 8.1 de la Convención.

3. Violación del derecho a la protección judicial, establecido en el artículo 25.1 de la Convención.

4. Incumplimiento de adecuación del derecho interno a la Convención Americana sobre Derechos Humanos, establecido en su artículo 2.

Finalmente, dispuso la instancia jurisdiccional interamericana, en virtud de la responsabilidad determinada, la obligación para el Estado venezolano de reparar los perjuicios causados, abstenerse de impedir la postulación de López Mendoza a cualquiera de los procesos electorales ex post, acordar la revocatoria o nulidad de los actos administrativos del caso acordados por el contralor general de la República y adecuar la LOCGRSNCF a las normas convencionales, mediante la reforma del artículo 105 del referido instrumento legal. 


\section{DERECHO ELECTORAL}

\section{LA PROCEDENCIA DE INHABILIDADES PÚBLICAS IMPUESTAS EN SEDE ADMINISTRATIVA CONFORME A LA CONVENCIÓn AMERICANA SOBRE DERECHOS Humanos}

El artículo 23 de la Convención Americana sobre Derechos Humanos consagra el contenido básico reconocido en el contexto interamericano a los derechos políticos y su efectivo ejercicio. Como parte del catálogo de libertades que se amparan bajo la denominación "derechos políticos", destaca especialmente el derecho al sufragio en su doble dimensión, activa y pasiva. Es decir, el derecho a elegir en elecciones libres, universales, directas, secretas y periódicas. Y el derecho a ser elegido, cuestión que obliga a los Estados parte de la Convención a garantizar la postulación de los individuos y partidos, sin más limitaciones que las derivadas racionalmente de los dispositivos normativos, y procurar una competencia electoral ajustada a los principios de igualdad e integridad. Para este último propósito, la Convención admite como potestad soberana de los Estados la regulación de su sistema político-electoral; sin embargo, en cuanto a los límites reconocidos al derecho del sufragio para su configuración legal y efectivo ejercicio, es clara en manifestar que solo son admisibles límites por razones de edad, nacionalidad, residencia, idioma, instrucción, capacidad civil o mental, o condena por juez competente en proceso penal.

Ciertamente, los conceptos esbozados por la Convención no son ajenos a controversias. Sin embargo, en la práctica prospera una especie de acuerdo material que recoge algunas consideraciones mínimas de la democracia, que permiten afirmar o reconocer a dichos conceptos como precondiciones del juego político e institucional de los Estados democráticos y constitucionales modernos. En efecto, los mínimos recogidos en la Convención y complementados por la Carta Democrática Interamericana de 2001 son una especie de hoja de ruta democrática para los Estados que integran el Sistema Interamericano. Por ese motivo y en consideración del fallo comentado, es necesario evaluar las restricciones legítimas o permisibles a los elementos cualitativos de los derechos políticos a la luz de los principios y disposiciones normativas del Sistema.

Igualmente, por constituir un asunto que transversaliza el fallo objeto de análisis, otra cuestión relevante para comprender la discusión que subyace al pronunciamiento de la alta corte interamericana refiere a la ética pública y la moral administrativa o, en términos contemporáneos, a la transparencia y a la probidad exigida por estándares nacionales e 


\section{DERECHO ELECTORAL}

internacionales para el ejercicio legal y democrático de la función pública. Sobre este tópico, especialmente en Latinoamérica, una región caracterizada por altos niveles de corrupción política, las normas internacionales y nacionales han desarrollado múltiples sistemas de control y sanción con niveles de actuación administrativas y judiciales, en procura de cautelar como bienes jurídicos esenciales la transparencia y el fortalecimiento institucional de la democracia. Esta legítima acción de los Estados recoge, en algunos casos, procedimientos y sanciones que suelen afectar uno o más atributos reconocidos a los derechos políticos. Esta afectación desde luego alcanza, especialmente por la tipificación de hechos de corrupción, la limitación del derecho a ser elegido o en definitiva el derecho al ejercicio de la función pública.

Lo anterior no es objeto de discusión cuando dicha privación de uno o algunos de los atributos reconocidos a los derechos políticos deriva de un proceso penal ajustado a las garantías procesales esenciales, y la sanción de inhabilitación o suspensión es impuesta por un órgano de naturaleza jurisdiccional en ejercicio de la competencia penal. Esto último resume el contenido y la interpretación del artículo 23.2 de la Convención, el cual dominó en el fallo comentado. Tal como afirma Nogueira Alcalá:

ningún Estado parte de la Convención puede contemplar en su ordenamiento jurídico la afectación de los atributos básicos o esenciales que integran los derechos políticos asegurados y garantizados convencionalmente, como es el derecho de sufragio pasivo, generando una inhabilidad sobreviviente, a través de un procedimiento y resolución de un órgano administrativo (2011, p. 357).

Adicionalmente, el Estado venezolano es parte de la Convención y por ende se obliga a su cumplimiento. Además, las disposiciones de los instrumentos internacionales en materia de derechos humanos del Sistema Interamericano, por mandato de la propia Constitución vigente, son de ejecución directa e inmediata en el ordenamiento jurídico interno. En palabras de Guzmán Dalbora, esto se entiende como la integración del ordenamiento interno por las "normas fundamentales del ordenamiento jurídico supraestatal, con sus principios imperativos o inderogables y las costumbres vigentes en la comunidad de naciones" (2013, p. 139).

Parte de los cuestionamientos relevantes del fallo atienden la afirmación de Nogueira Alcalá y esto es: ¿puede un órgano administrativo como la 


\section{DERECHO ELECTORAL}

Contraloría, dentro del marco convencional, imponer una sanción como la privación temporal del derecho a ser elegido? La respuesta que imperó en el fallo es no, por esa razón, ordena al Estado la reforma de la legislación que regula el ejercicio de la función de control fiscal. Pero, esto exige por lo menos un ejercicio de proporcionalidad que estime las variables intervinientes, especialmente los amplios poderes otorgados por el legislador a distintos órganos para procurar la probidad administrativa. $Y$ es que, para alcanzar dicho fin, los procedimientos y sanciones a disposición de la CGR pueden estar justificados ampliamente. Es decir, las posibilidades de restricción de atributos de los derechos políticos en manos de la administración controladora cautelan con eficiencia la probidad administrativa y el fortalecimiento de las instituciones, por lo que la norma aplicada responde a un fin legítimo.

Ahora bien, respecto a la idoneidad de la sanción, la respuesta se complejiza. Pues la CGR está constitucional y legalmente habilitada para el ejercicio de su función y adicionalmente robustecida en términos de poder para incidir de manera eficiente en la realización de sus fines de control. Entonces, ese amplio poder de control y sanción, derivado del sistema normativo vigente, le permite imponer multas razonables adecuadas a la magnitud del daño causado a las arcas públicas, pero, y este es un cuestionamiento, la graduación de las sanciones contenida en la LOCGRSNCF le permite, actuando en sede administrativa, alcanzar, por la gravedad del acto, la imposición de penas accesorias que entendemos reservadas al ámbito de la justicia penal. Nuevamente la respuesta es no, lo cual objeta igualmente la idoneidad de la sanción.

Es entendido que, en atención a la magnitud e importancia del hecho contra la probidad, el Estado como medida de ultima ratio pueda tipificar una conducta, estableciendo en consecuencia una sanción penal. Esta sanción debe ser determinada e impuesta por el juez penal después de un debido proceso. Tal como refieren los antecedentes consultados del caso, el Estado venezolano solo desplegó órganos y procedimientos administrativos para aplicar una sanción que se entiende contra convencional, pues pese a su naturaleza exclusivamente penal, es impuesta en sede administrativa.

Con relación a la determinación del medio menos restrictivo para los derechos fundamentales, es de hacer notar que la sanción que ya consideramos inidónea, igualmente trasvasa los equilibrios construidos a partir de principios que integran el Sistema Interamericano y el propio 


\section{DERECHO ELECTORAL}

ordenamiento jurídico venezolano, al imponer discrecionalmente un medio de sanción más restrictivo que afecta y limita el ejercicio de la ciudadanía, sin ponderar que el propio órgano administrativo de control, en ejercicio de sus legítimas funciones, contaba con otras sanciones idóneas y menos restrictivas de las libertades como las sanciones de carácter pecuniario (multas).

El ejercicio anterior de proporcionalidad, desarrollado de forma muy breve, permite secundar los razonamientos y la decisión final contenida en el fallo. Es evidente que la sanción de suspensión del ejercicio de derechos políticos impuesta por un órgano administrativo no solo es contra convencional, también es desproporcionada y por tal arbitraria; y violatoria de las reglas del debido proceso. Tal como afirman Fernández y Boutaud: "la limitación a un derecho fundamental debe ser adecuada, necesaria y proporcionada para la consecución de un fin legítimo" (Fernández y Boutaud, 2018, p. 351). Esos mismos criterios permiten: "descartar la arbitrariedad del ejercicio del poder punitivo" (Fernández y Boutaud, 2018, p. 351).

Finalmente, otra cuestión particularmente curiosa que destaca en el fallo y al mismo tiempo justifica sus argumentos, es que la ausencia del procedimiento penal es tal, que pese a estar incurso López Mendoza en hechos constitutivos de delitos de corrupción, según las alegaciones de la propia CGR, se le impone una sanción accesoria a todas luces de carácter penal pero él mismo, nunca es sometido a la justicia penal para la determinación de la responsabilidad por los hechos de corrupción que en sede administrativa se le imputaron y que motivaron su inhabilitación política anticipada. Esto último, en palabras de Barrientos Pardo, configura una vulneración del derecho a la presunción de inocencia, pues se "adelantan los efectos que solo una sentencia condenatoria puede generar $y$, en consecuencia, pasa por alto que la culpabilidad debe ser demostrada en juicio por el Estado" (2011, p. 278).

\section{Límites de los derechos políticos en EL Sistema INTERAMERICANO de Derechos humanos}

El artículo 30 de la Convención Americana sobre Derechos Humanos habilita a los Estados parte para establecer limitaciones al ejercicio de los derechos y libertades reconocidas. Sin embargo, tales restricciones son legítimas en la medida que satisfagan determinadas condiciones que 


\section{DERECHO EIECTORAL}

emanan del propio contenido de la Convención o de los criterios interpretativos sostenidos por los órganos del Sistema. Estos criterios son los siguientes.

\section{a) Las restricciones deben estar establecidas en la ley}

La regulación normativa define los alcances y límites del ejercicio de los derechos políticos. La doctrina sostiene que los derechos políticos para su efectivo ejercicio requieren de una regulación normativa emanada del órgano legislativo (Asamblea o Parlamento), cuya composición democrática debe incidir en la definición del sistema político y electoral, en definitiva, en las reglas del juego político-institucional.

\section{b) Las restricciones deben perseguir un fin legítimo y regulado en la Convención}

Toda limitación legalmente establecida debe ampararse en las propias limitaciones que la Convención reconoce como finalidades generales legítimas: los derechos y libertades de las demás personas o las justas exigencias del bien común en una sociedad democrática. El párrafo 2 del artículo 23 de la Convención, tal como se afirmó en el apartado anterior, establece que la ley puede reglamentar limitaciones o restricciones al ejercicio de los derechos y oportunidades a tales derechos, exclusivamente en razón de la edad, nacionalidad, residencia, idioma, instrucción, capacidad civil o mental, o condena por juez competente en proceso penal. Esta disposición impide el ejercicio de funciones de carácter administrativo para la limitación de los derechos políticos, previniendo así actos arbitrarios, de abuso de poder o desviación de poder.

c) Las restricciones deben ser estrictamente necesarias en una sociedad democrática

Sostiene Nogueira Alcalá que:

para evaluar si se cumple con tal postulado o principio se debe analizar si el requisito que restringe temporalmente el ejercicio del derecho a ser elegido en el caso de análisis satisface una necesidad social imperiosa, esto es, está orientado a satisfacer un interés público imperativo (2011, p. 345). 


\section{DERECHO ELECTORAL}

d) Las restricciones deben ajustarse al principio de proporcionalidad

El derecho de la ciudadanía política no es absoluto, pero sus restricciones tampoco. El derecho a elegir y a ser electo se limita por situaciones que deben constituir 'motivos idóneos, suficientes y justificados'. O, dicho de otra manera: cualquier restricción al sufragio como derecho fundamental plantea el debate de 'la causa debida': a nadie se le puede privar el sufragio sin causa que lo justifique de manera proporcional. (Ríos, 2017, p. 121).

\section{Conclusiones}

El análisis del fallo objeto del presente comentario se centró en tres aspectos, el primero sobre el contexto del caso, el segundo referido a la procedencia de inhabilidades públicas impuestas en sede administrativa; y el tercero en torno a los límites o restricciones permisibles de los derechos políticos en el Sistema Interamericano de Derechos Humanos. Dichos aspectos interceptan en buena medida la controversia y las argumentaciones desarrolladas en el fallo.

En efecto, el desarrollo argumentativo que antecede secunda la decisión acordada por la Corte Interamericana de Derechos Humanos y reconstruye, a partir de algunos referentes teóricos dogmáticos y disposiciones normativas nacionales e internacionales, una parte fundamental de los razonamientos jurisdiccionales de la Corte. La medida adoptada por la Contraloría General de la República de Venezuela evidentemente tensiona la normativa supraestatal, especialmente la que encuentra como fuente a la Convención Americana sobre Derechos Humanos.

El mencionado instrumento internacional consagra una clara distinción de sedes 0 instancias habilitadas para la limitación de derechos fundamentales, esto en referencia al artículo 23.2 que atribuye al poder judicial y en particular al juez penal la imposición de inhabilidades políticas como consecuencia de sanciones penales. Dicha limitación busca, como fue afirmado previamente, orientar racionalmente el poder punitivo del Estado preservándolo de la arbitrariedad y el abuso de poder al que se expone en el ejercicio de prerrogativas propias de la actividad administrativa y la discrecionalidad. 


\section{DERECHO EIECTORAL}

En todo caso, y esto tiene un propósito reiterativo, la construcción doctrinal y jurisprudencial que predominó en el fallo es la que entiende la suspensión de alguna de las características y atributos de los derechos políticos como una cuestión gravosa que debe necesariamente derivar del castigo de un acto tipificado como delito, determinado por un tribunal con las debidas garantías procesales y conforme al principio de proporcionalidad.

\section{REFERENCIAS BIBLIOGRÁFICAS}

Barrientos, I. (2011). Suspensión del derecho de sufragio por acusación penal. Vulneración constitucional de la presunción de inocencia. Estudios Constitucionales, 9(2), 249-328.

Corte Interamericana de Derechos Humanos (2011). Sentencia n. ${ }^{\circ} 233$ (serie c) del primero de septiembre. Recuperado de https://corteidh.or.cr/docs/casos/articulos/seriec_233_esp.pdf

Fernández, J. y Boutaud, E. (Julio, 2018). Los apremios personales en la jurisprudencia del Tribunal Constitucional: un análisis crítico desde la dogmática de los principios y límites penales. Política Criminal, 13(25), 350-386.

Gómez, D. (Jul.-Dic., 2011). La sentencia n. ${ }^{\circ} 154 / 2011$ de la Sala Constitucional del TSJ en el contexto del fallo n. ${ }^{\circ} 233$ (serie c) de la Corte Interamericana de Derechos Humanos (Caso: Leopoldo López Mendoza). Revista de Ciencias Jurídicas de la Universidad Rafael Urdaneta, (2), 105-123.

Guzmán, J. (2013). El caso de Chile. En Sistema Interamericano de Protección de los Derechos Humanos y Derecho Penal (pp. 135-164). Bogotá: Fundación Konrad Adenauer.

Nogueira, H. (2011). Informe pericial caso López Mendoza vs. Venezuela de Dr. Humberto Nogueira Alcalá. Estudios Constitucionales, 9(1), 339-362.

Ríos, L. (Ene.-Jun., 2017). El canon europeo e interamericano de la privación del sufragio pasivo. Revista Mexicana de Derecho Constitucional, (36), 109-140. 